\title{
Phlebotomine fauna (Diptera: Psychodidae) and species abundance in an endemic area of American cutaneous leishmaniasis in southeastern Minas Gerais, Brazil
}

\author{
Carlos Frederico Loiola/ ${ }^{+}$, Delano Anibal da Silva, Eunice Aparecida Bianchi Galati* \\ Laboratório de Doenças Parasitárias e Saúde Pública, Faculdade de Biomedicina, Universidade José do Rosário Vellano, Unifenas, \\ Rodovia MG 179 km 0, 37130-000 Alfenas, MG, Brasil *Departamento de Epidemiologia, Faculdade de Saúde Pública, \\ Universidade de São Paulo, São Paulo, SP, Brasil
}

This study was undertaken to identify the phlebotomine fauna and species abundance in domiciliary and peridomiciliary (hen-house and guava-tree) environments, on a lake shore, a cultivated area of coffee and banana, and a forested area of Conceição da Aparecida municipality, southeastern of the state of Minas Gerais, to provide information for the control and epidemiological surveillance of leishmaniasis in this area. The captures were carried out monthly between May 2001 and November 2002, with automatic light and Shannon traps. A total of 1444 sand flies were captured, 951 (76.5\%) with automatic light traps and 493 (23.5\%) with the Shannon trap. Thirteen species were captured, the most frequent being Nyssomyia whitmani (62.7\%), Migonemyia migonei (21.4\%), Pintomyia fischeri (6.9\%), and Evandromyia lenti (3.6\%). Species abundance was determined using the automatic light traps installed in the six environments. The most abundant species according to the standardized index of species abundance were $\mathrm{Ny}$. whitmani (1.0) and $\mathrm{Mg}$. migonei (0.82). In view of the dominance of these two species, known vectors of cutaneous leishmaniasis in other Brazilian areas, their participation in the transmission of the disease in this county is suggested. The diversity and evenness indexes in the domicile were the lowest due to the high frequency (83\%) of $\mathrm{Ny}$. whitmani. The capture of Lutzomyia longipalpis, rarely recorded in the southeastern and southern regions of Minas Gerais, is also noteworthy.

Key words: fauna - leishmaniasis - Phlebotominae - vector ecology

Phlebotomines, with $c a .900$ species described worldwide, 470 of which inhabiting the Americas (Galati 2003), constitute a group of bothersome insects with several species acting as vectors of arboviruses, bartonellosis, and the leishmaniases (Forattini 1973).

Knowledge of phlebotomine diversity and the relative abundance of the species, is necessary to understand the natural history of the parasites transmitted by these insects (Feliciangeli 1987), as well as their anthropophilic or zoophilic behavior, the effect of the vegetation on species distribution and identification of their resting places, especially in areas endemic for the leishmaniases (Memmot 1991).

The aim of this study is to present the relative abundance and diversity of the phlebotomine fauna in the rural environment of Conceição da Aparecida municipality, an endemic area for cutaneous leishmaniasis in the state of Minas Gerais, and identify the proximity of the most abundant species to the human dwellings.

+Corresponding author: carlos.loiola@unifenas.br Received 8 December 2006

Accepted 29 March 2007

\section{MATERIALS AND METHODS}

The area studied belongs to the Regional Health Directory of Alfenas, located in the southeastern region of the state of Minas Gerais, which borders on the state of São Paulo. Conceição da Aparecida municipality is situated at $21^{\circ} 06^{\prime} \mathrm{S}, 46^{\circ} 13^{\prime} \mathrm{W}, 966 \mathrm{~m}$ a.s.l., north of the Serra da Mantiqueira (Fig. 1). The site studied is located in a coffee farm, Mata's farm (Fig. 2) situated close to Carmo do Rio Claro municipality, which borders the Furnas hydroelectric reservoir.

The captures of the sand flies were carried out monthly from May 2001 to November 2002 using automatic light traps (CDC type) and Shannon traps.

During three consecutive nights, a total of 10 automatic light traps were installed in several habitats. The captures were extended until the dawn the following day. The numbers of traps used in each of these latter were: two in a domicile, one in a hen-house, one in a peridomiciliary guavatree, a total of three in the coffee and banana plantations, one on the edge of a lake, and two in urban forest.

Captures using Shannon traps were always made in a peridomiciliary environment, on two successive nights, beginning about dusk. On one of the nights, the captures were undertaken during a two-hour period, and on the other, the captures were extended until the dawn the following day.

The specimens captured were transported to the Laboratory of Parasite Diseases and Public Health of the José do Rosario Vellano University, Unifenas, Alfenas, MG, for screening, clarification, slide mounting, and identification in accordance with Galati (2003). 


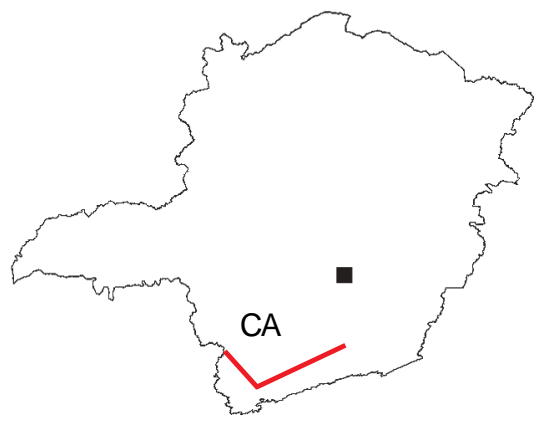

$\mathrm{CA}=$ Conceição da Aparecida Serra da Mantiqueira

Belo Horizonte

Fig. 1: location of Conceição da Aparecida municipality on the map of the state of Minas Gerais in relation to the Serra da Mantiqueira.

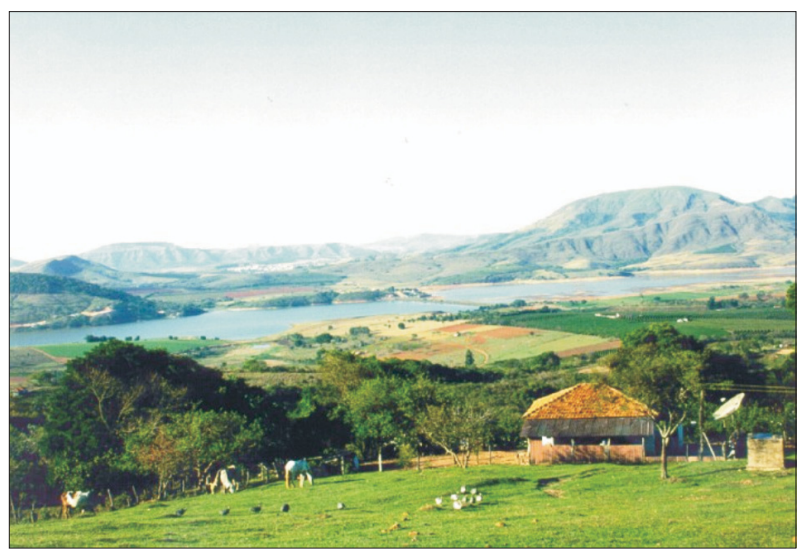

Fig. 2: sites studied with a view of the Furnas hydroelectric reservoir, Mata's farm.

The index of species abundance (ISA) was calculated based on the data obtained from the captures in the automatic light traps in the six environments sampled. For calculation of this index, the formula defined by Roberts and Hsi (1979) was used:

$$
\mathrm{ISA}=\mathrm{a}+\mathrm{Rj} / \mathrm{K}
$$

a: number of habitats researched in which the species was not present, multiplied by c, c: for each habitat, a ranking of species varying between 1 and $\mathrm{N}$ (attributing the value of 1.0 to the most abundant species) was established. The variable $\mathrm{c}$ is the greatest value obtained among the sum of all the positions in the ranking, for a given habitat, + 1.0; $\mathrm{Rj}$ : sum of a given species' positions in all habitats; K: number of habitats sampled.

In order to convert the ISA values on to scale of 0 to 1 , another index was used, denominated by the authors "the standardized index of species abundance - SISA". The more abundant species present values closer to 1 and vice-versa. The formula for calculating SISA is:

$$
\text { SISA }=c-I S A / c-1
$$

For the comparison of the total number of phlebotomines captured per automatic light trap in the several environments, the $\chi^{2}$ test was used. Diversity was estimated using Shannon index $(\mathrm{H})$, and evenness, Pielou index (J) (Hayek \& Buzas 1997).

\section{RESULTS}

The phlebotomine fauna was represented by 13 species: Evandromyia lenti (Mangabeira, 1938), Ev. sallesi (Galvão \& Coutinho, 1939), Ev. termitophila (Martins, Falcão \& Silva, 1964), Lutzomyia longipalpis (Lutz \& Neiva, 1912), Migonemyia migonei (França, 1920), Nyssomyia intermedia (Lutz \& Neiva, 1912), Ny. neivai (Pinto, 1926), Ny. whitmani (Antunes \& Coutinho, 1939), Pintomyia bianchigalatiae (Andrade-Filho, Aguiar Dias \& Falcão, 1999), Pi. fischeri (Pinto, 1926), Pi. misionensis (Castro, 1959), Pi. monticola (Costa Lima, 1932), and Psychodopygus lloydi (Antunes, 1937).

A total of 1444 phlebotomines were captured, 951 of them with automatic light traps and 493 with Shannon traps. The ratio between males and females was practically the same in the two different traps, with $62.2 \%$ of females in the light traps and $62.1 \%$ in the Shannon trap. The males represented 37.8 and $37.9 \%$ in the respective traps.

As is shown in the Table, the highest frequency, a total of 446 insects, giving a mean of 223 insects per trap, was captured in the peridomiciliary environments, representing twice the total captured in the domicile (105.5 sand flies/trap); 3.0 times that of the forest (74.0 sand flies/trap); 4.2 times that of the lake edge (53.0 sand flies /trap), and 7.2 times that of the plantations (31.0 sand flies/trap). These differences were statistically significant $(\mathrm{p} \leq 0.001)$. The domicile, with the second highest value, also possesses statistical significance in relation to those of the lake edge and plantation $(\mathrm{p}<0.001)$ and forest $(p<0.02)$. The total of phlebotomines/trap captured in the forest was greater than that of the plantation ( $\mathrm{p}<0.001)$ and lake, however this latter did not present statistical significance at a $5 \%$ level. In the peridomicile $80 \%$ of the sand flies were captured in the hen-house and $20 \%$ under the guava-tree.

The highest species richness, of eight species, was observed in the hen-house and plantation and the lowest, of five species, under the guava-tree and on the lake shore. The forest presented the highest diversity and the second evenness values, 1.434 and 0.737 respectively, but on the edge of the lake the inverse occurred, respective values being 1.319 and 0.819 . The domicile presented the lowest diversity and evenness indexes, 0.672 and 0.345 , respectively (Table).

The most abundant species were Ny. whitmani with a SISA of 1.0 and Mg. migonei with a SISA of 0.82 (Fig. 3).

$N y$. neivai was the only species one captured exclusively in the Shannon trap, with a total of three specimens $(0.2 \%)$. Since this species was not captured in the automatic light traps, it did not participate in the abundance calculation among species. The remaining results obtained from the captures in the Shannon trap, as well as the study of time frequency, among other species, will be presented and discussed in a future paper. 


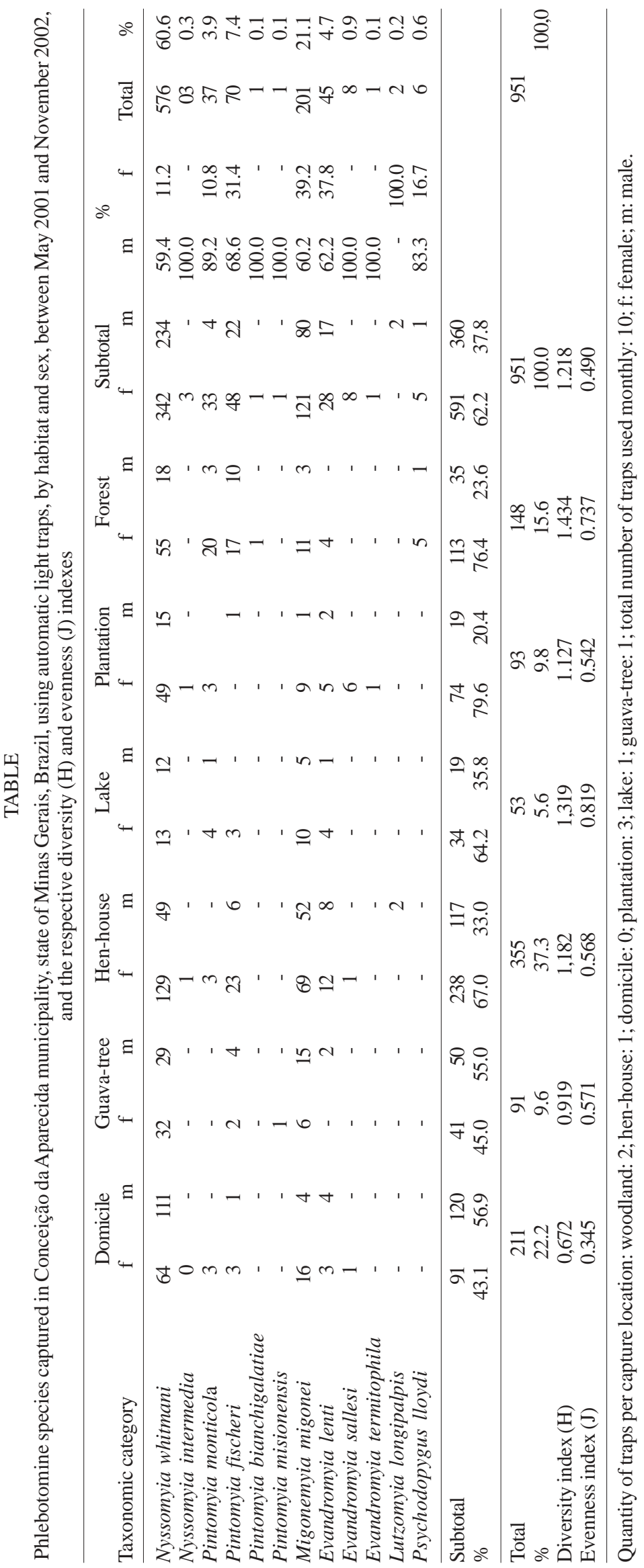




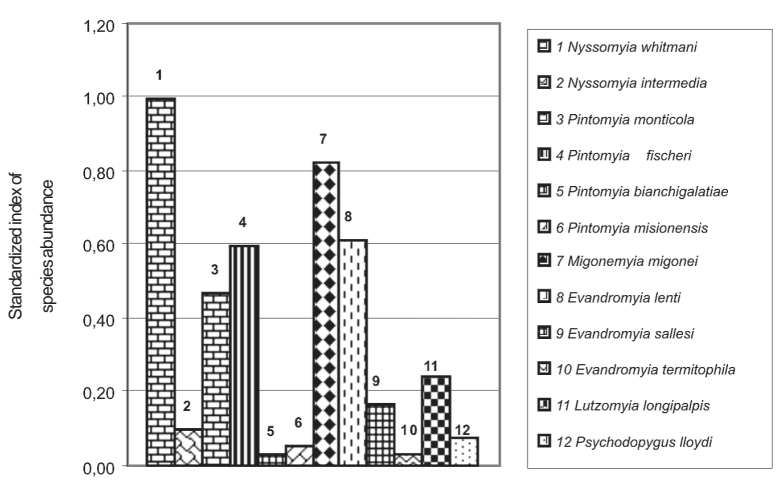

Fig. 3: standardized abundance indexes of the species captured using automatic light traps in Conceição da Aparecida municipality, state of Minas Gerais, between May 2001 and November 2002.

\section{DISCUSSION}

The presence of 13 phlebotomine species is close to that found in the states of Paraná and São Paulo (Mayo et al. 1998, Massafera et al. 2005). This may be a result of environmental alterations that have occurred in the region, as has also happened in the state of São Paulo (Gomes 1994, Condino et al. 1998, Mayo et al. 1998, Neves et al. 2002).

Ny. whitmani has been regarded as one of the most important vectors of American cutaneous leishmaniasis in a great part of Brazil and $\mathrm{Mg}$. migonei plays a secondary role in the transmission of this endemic disease in the Southeast and Northeast regions of Brazil (Rangel \& Lainson 2003). Thus the predominance of Ny. whitmani and $\mathrm{Mg}$. migonei suggests the participation of these species in the transmission of this disease in the area studied.

The predominance of some species in the anthropic environment is a relevant factor for leishmaniasis transmission and has already been mentioned in other studies regarding the phlebotomine fauna (Gomes \& Galati 1989, Gomes et al. 1989, Mayo et al. 1998).

The highest frequency $(83 \%)$ of $N y$. whitmani in the domicile explains its lowest diversity and evenness indexes, despite a relatively great richness, i. e., of seven species.

The highest rate of standardized abundance observed in the present study was for Ny. whitmani (1.0) and is very close to that found for the populations of this species in the tropical savannah of the Mid-West Region of Brazil that has a focus of American cutaneous leishmaniasis, where it probably behaves as a disease vector (Galati et al. 1996, 2003).

$N y$. intermedia and $N y$. nevai, both considered probable vectors of American cutaneous leishmaniasis, the former in the states of Espírito Santo, Rio de Janeiro, and coastal areas of São Paulo, the second in plateaux of the state São Paulo, in the Southern Region of Brazil, and Bolivia and Argentina. The sympatric occurrence of both species has been registered in some areas of the Ribeira Valley in the state São Paulo. In Minas Gerais, both species occur but in this region studied, only $N y$. neivai has been registered (Marcondes et al 1998).
The density obtained in this present study in the forest (74.0 insects/trap) is very different from that of forested areas, using the same technique, on the Serra de Maracaju and Serra da Bodoquena, both in the state of Mato Grosso do Sul (3.6 insects/trap) (Galati et al. 1996, 2006), perhaps explained by distinct vegetation covering these areas.

The highest means of $N y$. whitmani and Mi. migonei obtained in the peridomiciliary environments, seem to indicate the great invasive potential of both species.

In face of the diversity of the fauna and the predominance of a known vector species of American cutaneous leishmaniasis, Ny. whitmani, and also by virtue of the presence of the main vector of visceral leishmaniasis, Lu. longipalpis, even though this latter only represented $0.2 \%$ of the phlebotomine specimens captured and despite no case of visceral leishmaniasis having been notified in Conceição da Aparecida municipality (SES/MG 2005), we would emphasize the importance of the improvement and further extension of entomological vigilance regarding this fauna in the region.

The presence of Lu. longipalpis, species of great importance in American visceral leishmaniasis, captured in low density in this locality, will be commented in a short communication to be published by the authors.

\section{ACKNOWLEDGEMENTS}

To Melissa Vieira Leite, Marcony Raimundo Figueiredo de Carvalho, Eduardo dos Reis, and João Luis Rosenbaum Filho, academics of the University, for their collaboration in the captures and Dr Luciano Resende Ferreira, owner of the Mata's farm.

\section{REFERENCES}

Condino MLF, Sampaio SMP, Henriques LF, Galati EAB, Wanderley DMV, Corrêa FMA 1998. Leishmaniose tegumentar americana: flebotomíneos do estado de São Paulo, Brasil. Rev Soc Brasil Med Trop 31: 355-360.

Feliciangeli MD 1987. Ecology of sandflies (Diptera: Psychodidae) in a restricted focus of cutaneous leishmaniosis in Northern Venezuela. I. Description of the study area, catching methods, and species composition. Mem Inst Oswaldo Cruz 82: 119-124.

Forattini OP 1973. Entomologia Médica. Psychodidae, Phlebotominae, Leishmaniose, Bartonelose, Vol. IV, Edgard Blucher, São Paulo, 658 pp.

Galati EAB 2003. Classificação de Phlebotominae. In EF Rangel, R Lainson, Flebotomíneos do Brasil, Fiocruz, Rio de Janeiro, p. 23-51.

Galati EAB, Nunes VL, Boggiani PC, Dorval MEC, Cristaldo G, Rocha HC, Oshiro ET, Damasceno-Júnior GA 2006. Phlebotomines (Diptera: Psychodidae) in forested areas of the Serra da Bodoquena, state of Mato Grosso do Sul, Brazil. Mem Inst Oswaldo Cruz 101: 175-193.

Galati EAB, Nunes VL, Cristaldo G, Rocha HC 2003. Aspectos do comportamento da fauna flebotomínea (Diptera: Psychodidae) em foco de leishmaniose visceral e tegumentar na Serra da Bodoquena e área adjacente, estado de Mato Grosso do Sul, Brasil. Rev Pat Trop 32: 235-261.

Galati EAB, Nunes VL, Dorval MEC, Oshiro ET, Cristaldo G, Espíndola MA, Rocha HC, Garcia WB 1996. Estudo dos flebotomíneos (Diptera, Psychodiae), em área de leishmaniose tegumentar, no estado de Mato Grosso do Sul, Brasil. Rev Saú Públ 30: 115-128. 
Gomes AC 1994. Sand fly vectorial ecology in the state of São Paulo. Mem Inst Oswaldo Cruz 89: 457-460.

Gomes AC, Galati EAB 1989. Aspectos ecológicos da leishmaniose tegumentar americana. 7 - Capacidade vetorial flebotomínica em ambiente florestal primário do sistema da Serra do Mar, região do Vale do Ribeira, estado de São Paulo, Brasil. Rev Saú Públ 23: 136-142.

Gomes AC, Barata JMS, Rocha e Silva EO, Galati EAB 1989. Aspectos ecológicos da leishmaniose tegumentar americana. 6 - Fauna flebotomínica antropofílica de matas residuais situadas na região centro-nordeste do estado de São Paulo, Brasil. Rev Inst Med Trop São Paulo 31: 32-39.

Hayek LAC, Buzas MA 1997. Surveing Natural Population, Columbia University Press, New York, p. 347-389.

Marcondes CB, Lozovei AL, Vilela JH 1998. Distribuição geográfica de flebotomíneos do complexo Lutzomyia intermedia (Lutz \& Neiva, 1912) (Diptera, Psychodidae). Rev Soc Brasil Med Trop 31: 51-58.

Massafera R, Silva AM, Carvalho AP, Santos DR, Galati EAB, Teodor U 2005. Fauna de flebotomíneos do município de Bandeirantes, no estado do Paraná. Rev Saú Públ 39: 571-577.
Mayo RC, Casanova C, Mascarini LM, Pignatti MG, Rangel O, Galati EAB, Wanderley DMV, Corrêa FMA 1998. Flebotomíneos (Diptera, Psychodidae) de área de transmissão de leishmaniose tegumentar americana, no município de Itupeva, região sudeste do estado de São Paulo, Brasil. Rev Soc Bras Med Trop 31: 339-345.

Memmott J 1991. Sand fly distribution and abundance in a tropical rain forest. Med Vet Entomol 5: 403-411.

Neves VLFC, Gomes AC, Antunes JLF 2002. Correlação da presença de espécies de flebotomíneos (Diptera: Psychodidae) com registro de casos da leishmaniose tegumentar americana no estado de São Paulo, Brasil. Rev Soc Bras Med Trop 35: 299-306.

Rangel EF, Lainson R 2003. Flebotomíneos do Brasil, Fiocruz, Rio de Janeiro.

Roberts DR, Hsi BP 1979. An index of species abundance for use with mosquito surveillance data. Environ Entomol 8: 1007-1013.

SES/MG-Secretaria Estadual de Saúde de Minas Gerais 2005. Relatório anual dos casos de leishmaniose notificados junto à SES/MG e FNS/MG, Belo Horizonte, 2005. 
